\title{
DESENVOLVIMENTO DE METODOLOGIA PARA CARACTERIZAÇÃO DO AÇO 22MnB5 GALVANNEALED DESTINADO A CONFORMAÇÃO A QUENTE*
}

Aldo Henrique de Almeida Barbosa ${ }^{1}$ Henrique Lacerda Eleutério ${ }^{2}$ João Francisco Batista Pereira ${ }^{3}$ João Luiz Costa Carvalho ${ }^{4}$

\section{Resumo}

A demanda do setor automobilístico por aços revestidos destinados à conformação a quente vem crescendo substancialmente nos mercados brasileiro e mundial, por eles possuírem boa conformabilidade e, após conformação, terem sua resistência significativamente aumentada. A busca por alternativas de revestimentos para essa aplicação está focada no revestimento galvannealed (GA), visando garantir a sua integridade durante o processo direto de conformação a quente. Nesse trabalho, foram desenvolvidos, em escala de laboratório, ciclos de recozimento e de galvannealing para o aço 22MnB5-GA, visando tornar o revestimento GA capaz de suportar as aplicações de conformação a quente para a indústria automobilística. Foram avaliados, também em escala de laboratório, tratamentos de austenitização desse aço. As melhores condições, tanto de produção do revestimento quanto do tratamento térmico para conformação a quente, foram validadas industrialmente. Os resultados mostraram a viabilidade de se utilizar o aço 22MnB5-GA em aplicações de conformação a quente, com excelente qualidade superficial, propriedades mecânicas e microestrutura do substrato ajustadas à aplicação, inexistência de trincas no aço, boa aderência e aparência da camada de tinta e, também, bons desempenhos em termos de resistência à corrosão e de soldabilidade.

Palavras-chave: Conformação a quente; Aço 22MnB5; Galvanização a quente.

\section{DEVELOPMENT OF A CHARACTERIZATION METHODOLOGY FOR 22MnB5 GALVANNEALED STEEL DESTINED TO HOT STAMPING PROCESS}

\section{Abstract}

The demand from the automotive industry for coated steels for hot forming has grown substantially, because after forming these steels have a significant increase in mechanical strength. The search for alternative coatings to ensure the integrity of the $\mathrm{Zn}$ layer during hot forming is focused on the galvannealed coating (GA). In this work, annealing and galvanizing cycles were developed in laboratory scale aiming to make the GA coating to be able to withstand the high temperatures of the hot forming process. The austenitizing treatments were also evaluated in order to ensure the performance of the final product. The best conditions for producing the GA coating and the austenitization were validated. The results showed the feasibility of using the GA coating in hot forming applications with excellent surface quality, mechanical properties and microstructure of the substrate adjusted to the application, absence of cracks in steel, good adhesion and appearance of the paint, and good performances in terms of corrosion resistance and weldability.

Keywords: Hot forming; 22MnB5 steel; Hot dip galvanizing.

1 Engenheiro Metalurgista, Doutor em Engenharia Metalúrgica e de Materiais, Pesquisador Especialista do Centro de Tecnologia Usiminas, Ipatinga, MG, Brasil.

2 Engenheiro Metalurgista, Pesquisador do Centro de Tecnologia Usiminas, Ipatinga, MG, Brasil.

3 Engenheiro Metalurgista, Mestre em Engenharia Metalúrgica, Especialista de Produto da Gerência Geral de Atendimento ao Cliente, Garantia da Qualidade e Produto da Usiminas, Belo Horizonte, MG, Brasil.

4 Engenheiro Metalurgista, Engenheiro de Assistência Técnica a Clientes da Usiminas, Ipatinga, MG, Brasil. 


\section{INTRODUÇÃO}

Especial atenção tem sido dada ao desenvolvimento de revestimentos zincados para o aço 22MnB5 destinado à conformação e têmpera simultâneas (CTS), particularmente o da liga Fe-Zn, galvannealed (GA), em função da sua qualidade superficial ao final do processo, da proteção galvânica que proporciona às peças e pela facilidade de adaptação das linhas industriais de galvanização à sua produção. Contudo, os desafios são enormes, principalmente o de garantir a integridade estrutural da camada contendo $Z n$ após o processo de conformação a quente, uma vez que as temperaturas envolvidas são superiores à de fusão do Zn.

Tendo em vista a demanda por aços para CTS, esse trabalho objetivou a determinação das condições ótimas de processamento, tanto de recozimento e de galvannealing, ambos adaptados às condições de uma linha contínua de galvanização (CGL), quanto de tratamento de austenitização, esse último que precede ao processo de conformação. Todas as simulações foram realizadas em escala de laboratório e os melhores resultados validados industrialmente.

\section{MATERIAIS E MÉTODOS}

O desenvolvimento do aço 22MnB5-GA ocorreu em várias etapas, descritas abaixo.

\subsection{Ciclos de Recozimento Contínuo para o Aço}

Primeiramente, foi necessário determinar ciclos de recozimento contínuo para esse aço na CGL, que até então era produzido exclusivamente sem revestimento, como laminado a frio, via recozimento em caixa, ou laminado a quente. Além da microestrutura e propriedades mecânicas, especial atenção foi dada à condição de superfície, com controle rigoroso da atmosfera dos fornos da CGL. Nessa etapa, foi utilizado o simulador do processo de galvanização por imersão a quente (HDPS- Hot Dip Process Simulator).

\subsection{Revestimentos Metálicos}

Foram avaliados os revestimentos metálicos aluminizados, com diferentes teores de elemento de liga ( $\mathrm{Si}$ ), e os zincados, tais como o $\mathrm{Zn}$ puro (galvanized-GI), o ligado com Fe (GA), e os com adições de $\mathrm{Al}, \mathrm{Mg}, \mathrm{Mn}, \mathrm{Cr}$ e $\mathrm{Cu}$, todos em diversas concentrações. Para a determinação da temperatura de fusão de cada uma das ligas, juntamente com as fases intermetálicas passíveis de serem formadas durante a solidificação do revestimento, utilizou-se o software Thermocalc. Para cada um desses revestimentos foi desenvolvido um ciclo específico de processamento para CGL, com parâmetros otimizados para garantir a qualidade superficial do revestimento e o seu bom desempenho em aplicação de conformação a quente.

Dos revestimentos avaliados o que apresentou os melhores resultados de qualidade e de desempenho, associados à facilidade de produzi-lo com o mínimo de adaptações na CGL, foi o GA. Para esse aço foram realizadas novas simulações em faixas mais amplas e variações mais estreitas, tanto dos ciclos de galvannealing quanto do tratamento térmico de austenitização e de conformação a quente, visando ajustar as qualidades do revestimento e do aço às aplicações da indústria automobilística. 


\subsection{Ciclos de Galvannealing para o Aço 22MnB5-GA}

$\mathrm{Na}$ etapa de galvannealing, ainda em escala de laboratório, variou-se: (i) o modelo de tratamento térmico, com ciclos isotérmicos e ciclos com resfriamento imediatamente após aquecimento indutivo, na etapa do processo de galvannealing chamada de transformação do revestimento (TR); (ii) a temperatura de aquecimento indutivo (TAl) entre $525^{\circ} \mathrm{C}$ e $600^{\circ} \mathrm{C}$; (iii) os tempos de encharque e total na $\mathrm{TR}$, entre $3 \mathrm{~s}$ e $25 \mathrm{~s}$, e (iv) a taxa de resfriamento na TR entre $3^{\circ} \mathrm{C} / \mathrm{s}$ e $10^{\circ} \mathrm{C} / \mathrm{s}$. Essas variações estão esquematicamente mostradas na figura 1. Foram avaliados, também, os efeitos do ponto de orvalho da atmosfera dos fornos, da temperatura do banho de $\mathrm{Zn}$ e do tempo de imersão do aço no pote, sendo esse último função da velocidade da linha.

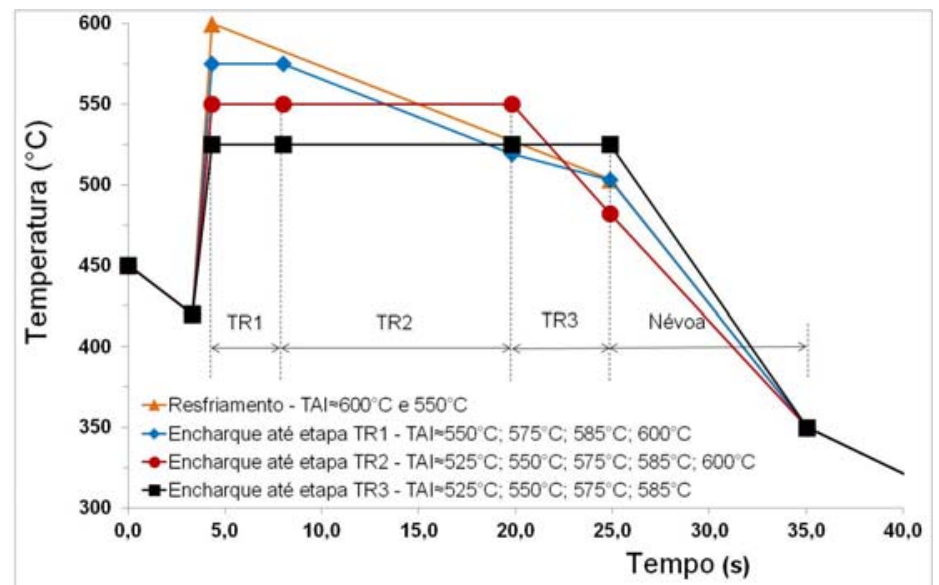

Figura 1. Ciclos de galvannealing esquemáticos, exemplificando os modelos de tratamento e os parâmetros avaliados na etapa de transformação do revestimento.

As melhores condições determinadas nesses ensaios foram testadas industrialmente. Os bons resultados industriais confirmaram os já obtidos em escala de laboratório. A partir disso, nas etapas seguintes foram utilizadas somente amostras produzidas industrialmente.

As amostras de aço 22MnB5-GA foram caracterizadas quanto à: (i) composição química do revestimento ( $\mathrm{Fe}, \mathrm{Al}$ e $\mathrm{Zn}$ ), via espectrometria de emissão ótica por plasma (ICP-OES); (ii) morfologia, microestrutura do revestimento e presença de trincas no substrato, via microscopia eletrônica de varredura com espectrômetro por dispersão de energia (MEV/EDS); (iii) aderência ao substrato, via teste de dobramento; (iv) perfil de composição química ao longo da espessura da camada, via MEV/EDS/Linescan e espectrômetro ótico por descarga luminescente (GDOES), e (v) qualidade superficial por inspeção visual.

A partir das concentrações de Fe foi possível determinar a proporção de cada fase $\mathrm{Fe}-\mathrm{Zn}$ presente nos revestimentos [1]. A identificação das fases foi realizada associando-se os teores de Fe medidos nos revestimentos às concentrações de $\mathrm{Fe}$ das fases, obtidas pelo diagrama de equilíbrio termodinâmico $\mathrm{Fe}-\mathrm{Zn}$, considerando que a fase $\zeta$ (zeta) contem $5 \%$ a $6 \%$ de Fe; a $\delta$ (delta) $7 \%$ a $12 \%$ de Fe; a $\Gamma_{1}$ (gama 1) $17 \%$ a $19 \%$ de Fe, e a Г (gama) 23 a $28 \%$ de Fe [2]. 


\subsection{Tratamento Térmico de Austenitização e Conformação a Quente}

No tratamento de austenitização foram avaliados: (i) a taxa e o modelo de aquecimento, que foi dividido em zonas; (ii) o tempo total e a temperatura final de tratamento; (iii) o tempo e a taxa de resfriamento entre o final de tratamento térmico e o início da conformação, e (iv) a taxa de resfriamento durante a conformação. Esses testes foram realizados tanto na Gleeble quanto em forno mufla, ambos com controle da atmosfera sobre o corpo de prova.

Para a conformação a quente, uma matriz refrigerada a água foi adaptada a uma prensa hidráulica de $40 \mathrm{t}$. Na figura 2a são mostradas a mufla, o conjunto prensa/matriz refrigerada e a disposição desses equipamentos para a realização dos ensaios. Na figura $2 \mathrm{~b}$ é mostrado o aspecto da peça conformada. A melhor condição foi repetida em substratos com diferentes espessuras, entre $1,0 \mathrm{~mm}$ e $2,3 \mathrm{~mm}$. A massa de camada do revestimento foi mantida constante e igual a $80,0 \mathrm{~g} / \mathrm{m}^{2}$.

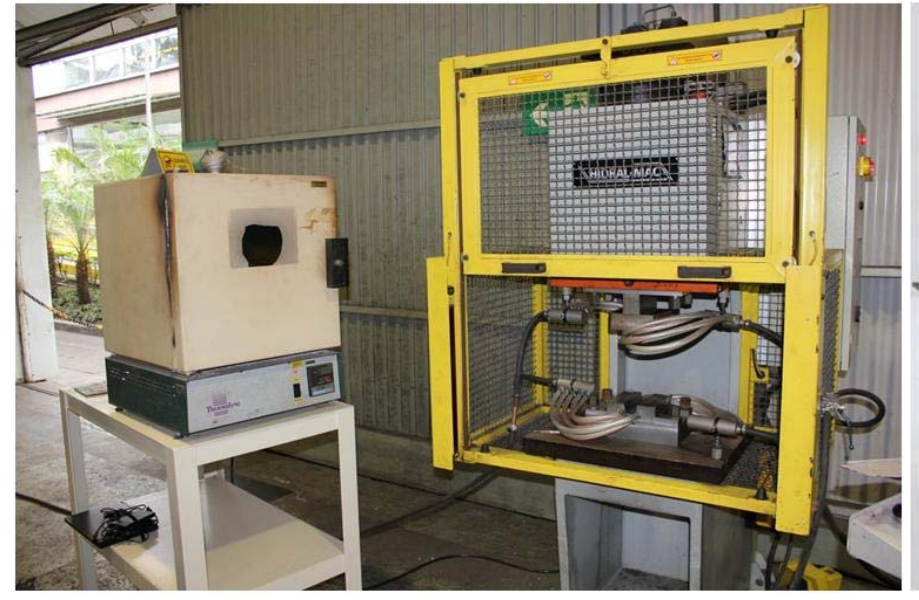

(a)

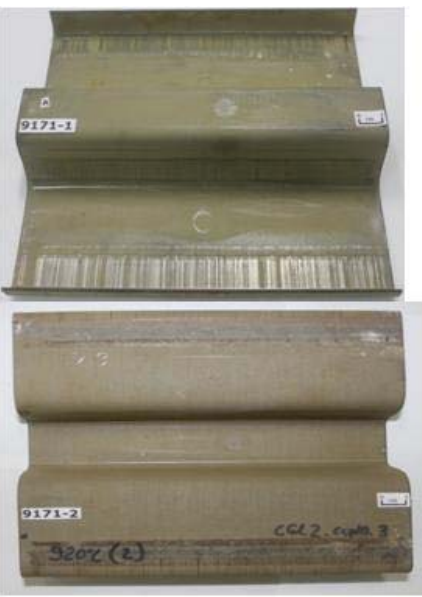

(b)

Figura 2. (a) Aparato utilizado nos ensaios de CTS em escala piloto, mufla e prensa com matriz refrigerada a água, e (b) duas faces de corpos de prova conformados a quente.

Para a caracterização dos revestimentos após o tratamento de austenitização e de conformação a quente, foram realizadas análises de: (i) qualidade superficial; (ii) morfologia, composição química e microestrutura da camada formada, via MEV/EDS; (iii) qualidade do substrato na interface com o revestimento, via microscopia ótica e MEV/EDS; (iv) microestrutura do substrato, via técnica metalográfica (ataque Nital-4\%) e MO; (v) propriedades mecânicas do substrato, utilizando corpos de prova subsize, que atendem a norma ASTM-A370, e (vi) aspecto e aderência da camada de tinta, com e sem a remoção da camada de óxidos formada na superfície do aço 22MnB5-GA durante a etapa de austenitização.

\section{RESULTADOS E DISCUSSÃO}

\subsection{Caracterização do Revestimento Galvannealed}

Na figura 3 são mostrados aspectos morfológicos característicos da superfície e da seção transversal do revestimento galvannealed formado sobre o aço 22MnB5, destinado à conformação a quente. A melhor condição de galvannealing obtida para 
essa aplicação permitiu controlar as reações explosivas de outburst, promovendo o crescimento homogêneo dos compostos $\mathrm{Fe}-\mathrm{Zn}$ e, assim, a formação de um revestimento de boa qualidade, isento de falhas e de crateras na superfície. Observa-se uma camada bastante compacta, tanto na superfície quanto na seção, mas com características ligeiramente modificadas em relação ao revestimento GA destinado à conformação a frio. Importante destacar que o processamento desse material foi adaptado para a obtenção dessas características, tendo sido ajustado, dentre outros, os valores de ponto de orvalho e dos parâmetros de galvannealing.

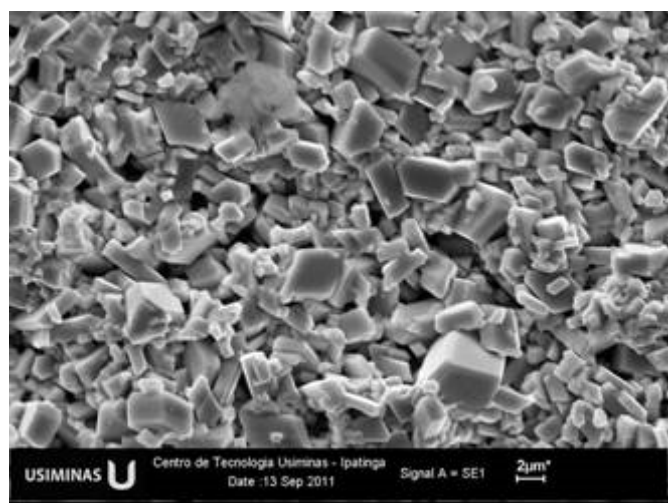

(a)

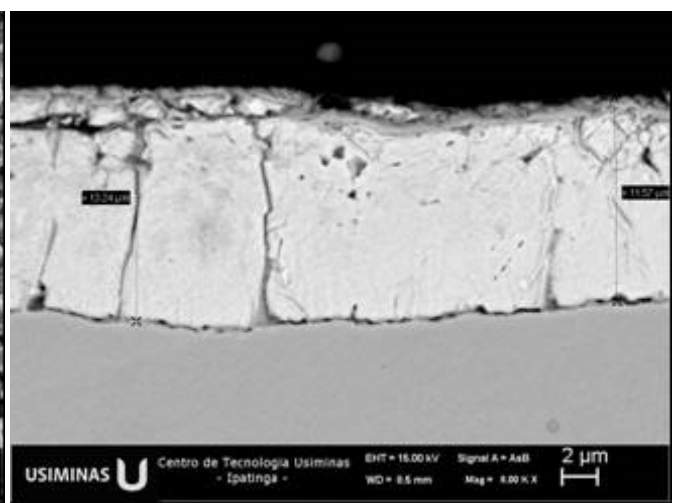

(b)

Figura 3. Aspectos morfológicos observados via MEV na: (a) superfície e (b) seção do revestimento GA formado sobre aço 22MnB5 antes da CTS.

O perfil de composição química ao longo da seção do revestimento confirma a boa qualidade do revestimento GA (figura 4). Em relação aos revestimentos GA produzidos sobre aços com baixa liga, as principais diferenças são a maior concentração de $\mathrm{Fe}$ e a percepção de uma camada muito fina de óxidos na superfície, basicamente de $\mathrm{Al}, \mathrm{Mn}$ e $\mathrm{Si}$, o que melhora o desempenho desse produto durante o tratamento de austenitização. Da mesma forma que o Fe difunde para o revestimento, esses elementos também se difundem e, por não formarem fases (ligas) com o Zn ou o Fe, chegam à superfície da camada galvanizada.
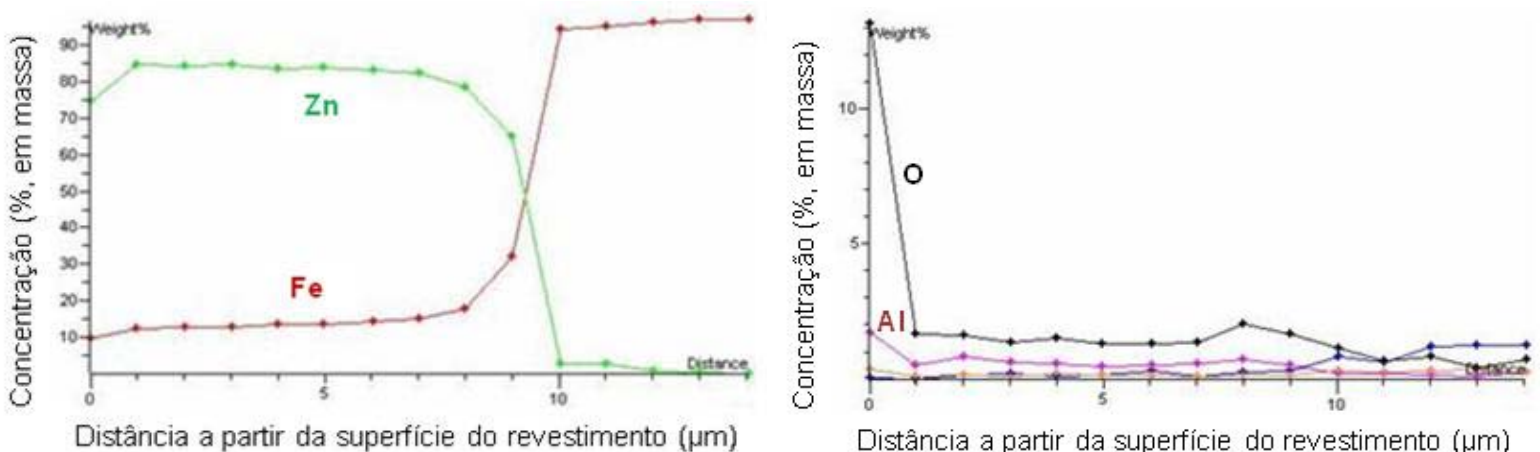

Distância a partir da superfície do revestimento $(\mu \mathrm{m})$

Figura 4. Análise via MEV/EDS/Line scan na seção do revestimento GA formado sobre aço 22MnB5 antes da CTS.

De um modo geral, o aumento do aporte de calor durante o tratamento de galvannealing, que está associado à temperatura de resfriamento nos fornos antes do pote de $\mathrm{Zn}$, à temperatura do induction heater $(\mathrm{IH})$, ao modelo e a taxa de 
resfriamento após o $\mathrm{IH}$, promoveu uma elevação na proporção da fase gama $(Г)$ e a redução da fase zeta $(\zeta)$. Essa microestrutura contribui para melhorar a qualidade do revestimento e do substrato após a estampagem a quente.

\subsection{Caracterização do Revestimento após Conformação a Quente}

Na figura 5 são mostrados os resultados de caracterização do aço 22MnB5-GA, produzido industrialmente na melhor condição da CGL, após o tratamento de austenitização em mufla e conformação e têmpera simultâneos em escala piloto. De um modo geral, há uma completa transformação morfológica, microestrutural e química do revestimento. Na superfície (figuras $5 a$ e $5 \mathrm{c}$ ) forma-se uma fina camada de óxidos de $\mathrm{Zn}, \mathrm{Al}, \mathrm{Mn}$ e $\mathrm{Si}$, que protege o revestimento, principalmente, contra a perda de massa durante o tratamento de austenitização, garantindo a integridade da camada.

Microestruturalmente o revestimento é formado por duas camadas bastante distintas (figuras $5 \mathrm{~b}$ e $5 \mathrm{c}$ ). Junto ao substrato, há uma camada de solução sólida Fe $\mathrm{e}_{\alpha} \mathrm{Zn}(30 \%$ a $40 \%$ de $\mathrm{Zn}$, em massa) homogênea e compacta, com espessura em torno de $18,0 \mu \mathrm{m}$. Por ser resultante da difusão de Fe do substrato, essa camada é altamente dependente das temperaturas e tempos envolvidos no tratamento, principalmente durante o aquecimento. Essa camada está completamente aderida ao substrato e com poucas trincas, o que se explica pelo fato de ser constituída unicamente por solução sólida $\mathrm{Fe}_{\alpha}-\mathrm{Zn}$ e não por diferentes fases $\mathrm{Fe}-\mathrm{Zn}$.

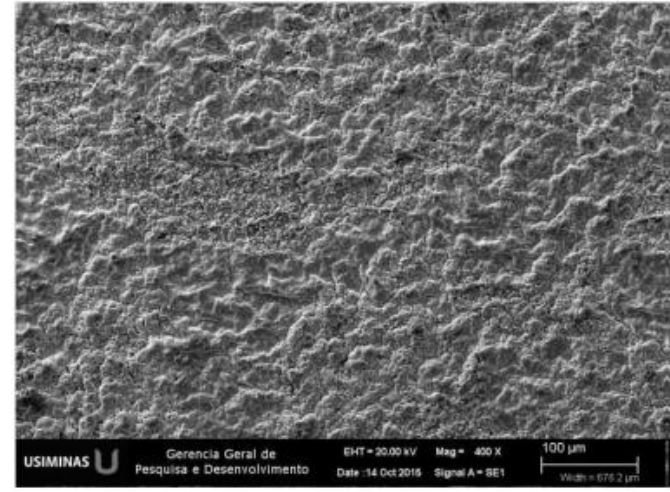

(a) Superfície. A. O.: 400 vezes

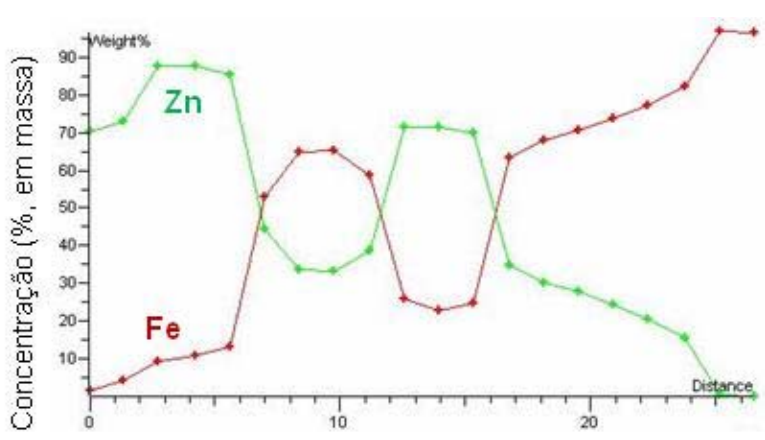

Distância a partir da superfície do revestimento $(\mu \mathrm{m})$

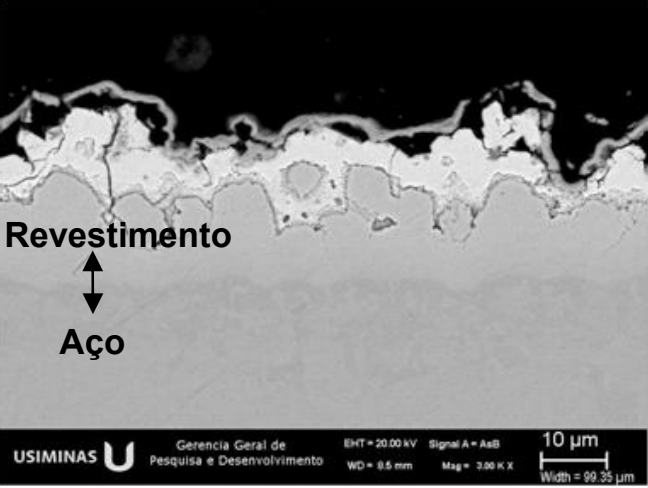

(b) Seção. A. O.: 20.000 vezes

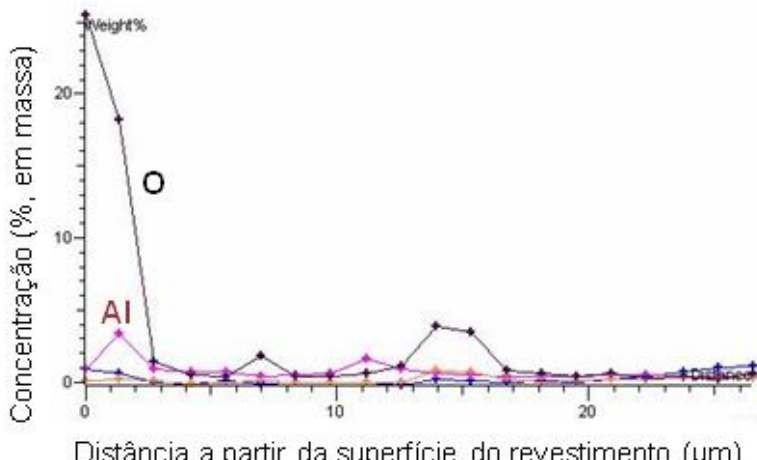

Distância a partir da superfície do revestimento $(\mu \mathrm{m})$

(c) Perfis de composição química ao longo da espessura do revestimento

Figura 5. Características morfológicas, químicas e microestruturais típicas, observadas via MEV/EDS na superfície e seção do aço 22MnB5-GA após a CTS. A. O.: Ampliação original. 
Acima da camada de solução sólida há outra constituída por compostos intermetálicos Fe-Zn e ilhas de solução sólida $\mathrm{Fe}_{\alpha}-\mathrm{Zn}$, cujo teor de $\mathrm{Fe}$ varia em torno de $30 \%$. A presença dessa região mais rica em $Z n$ na superfície, com espessura variando entre $5 \mu \mathrm{m}$ e $10 \mu \mathrm{m}$, além de melhorar a resistência à corrosão do produto, por promover proteção galvânica, minimiza o risco de nucleação de trincas, comuns em outros tipos de revestimentos para essa aplicação.

De grande importância é a constatação de que os tratamentos térmicos praticados com temperatura de forno de até $950^{\circ} \mathrm{C}$ e tempos de até 5,0 min, todos com atmosfera oxidante, foram adequados para promover a difusão suficiente de $\mathrm{Fe}$ do substrato, garantir a integridade estrutural do revestimento e produzir os efeitos adequados para suportar a aplicação da conformação a quente. Contudo, significativos ganhos de qualidade superficial do revestimento e do substrato são alcançados com temperaturas intermediárias e menores tempos de tratamento, além de um controle rigoroso da taxa de aquecimento. Esse último parâmetro deve ser controlado por etapas de aquecimento, que correspondem às zonas de cada forno no processo industrial, cada uma delas associada às propriedades das fases $\mathrm{Fe}-\mathrm{Zn}$ que se deseja transformar no revestimento.

Na figura 6 são mostrados aspectos característicos dos corpos de prova produzidos durante os testes de conformação a quente, após tratamento térmico de austenização e após serem conformados na prensa do Centro de Pesquisa da Usiminas. Percebe-se, em ambas as condições, uma superfície homogênea e de ótima qualidade, isenta de defeitos e com cobertura total do substrato.

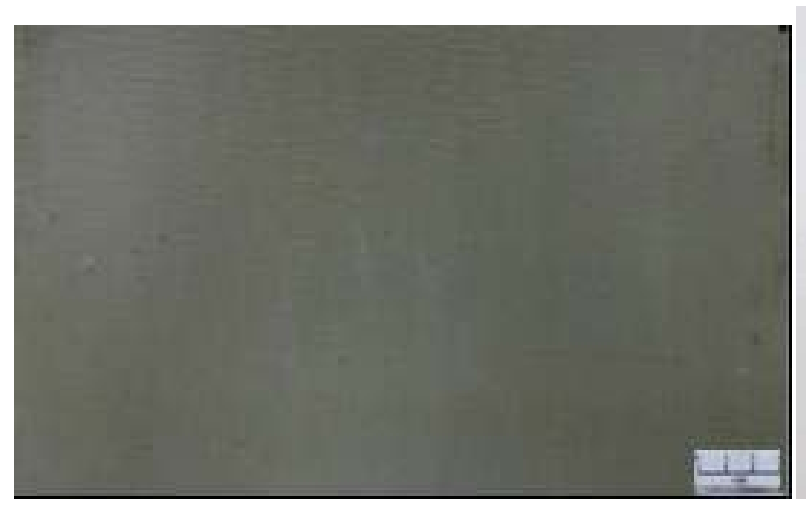

(a)

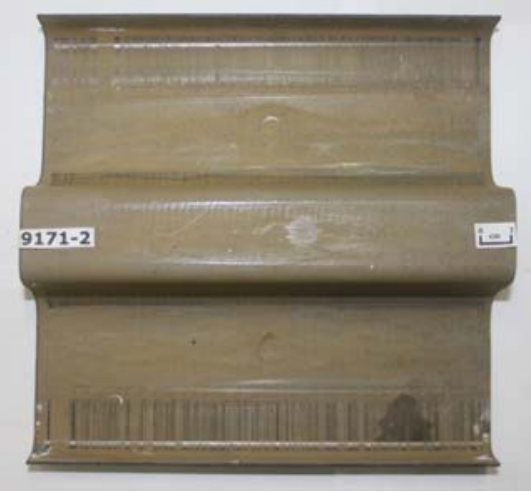

(b)

Figura 6. Aspectos característicos das superfícies (a) dos corpos de prova antes do tratamento de austenitização e (b) da peça após a CTS.

\subsection{Caracterização do Substrato após Conformação a Quente}

As propriedades mecânicas em tração das peças conformadas a quente processadas na melhor condição na CGL atenderam aos requisitos visados para aplicação do produto, conforme mostrado na tabela 1. Com relação à microestrutura, na figura 7 são mostrados os aspectos das seções transversais à direção de estiramento nos raios de curvatura, na parede e no fundo das peças estampadas. As análises por MO foram realizadas em regiões de dobramento, por estarem submetidas aos maiores esforços em tração, e de estiramento, por estarem sujeitas ao atrito entre a peça e o ferramental. De um modo geral, a microestrutura é 
composta predominantemente por martensita. Esses resultados indicam a efetividade do aparato construído para simular a operação de conformação a quente e a obtenção de produtos de boa qualidade.

Tabela 1. Propriedades mecânicas típicas para o aço 22MnB5-GA após conformação a quente e têmpera simultânea, obtidas com a melhor condição de processamento na CGL.

\begin{tabular}{ccccc}
\hline Condição & $\begin{array}{c}\text { Limite de } \\
\text { escoamento } \\
\text { (MPa) }\end{array}$ & $\begin{array}{c}\text { Limite de } \\
\text { resistência } \\
\text { (MPa) }\end{array}$ & $\begin{array}{c}\text { Al total (\%) } \\
\text { BM (25 } \mathbf{~ m m})\end{array}$ & $\begin{array}{c}\text { Dureza HV } \\
\mathbf{( 3 ~ k g f )}\end{array}$ \\
\hline Após galvanização & $439,8 \pm 7,8$ & $568,8 \pm 9,3$ & $25,0 \pm 1,2$ & $170,0 \pm 6,7$ \\
\hline Após conformação a quente & $1257,0 \pm 16,1$ & $1573,3 \pm 13,7$ & $7,2 \pm 0,9$ & $513,9 \pm 5,2$ \\
\hline
\end{tabular}

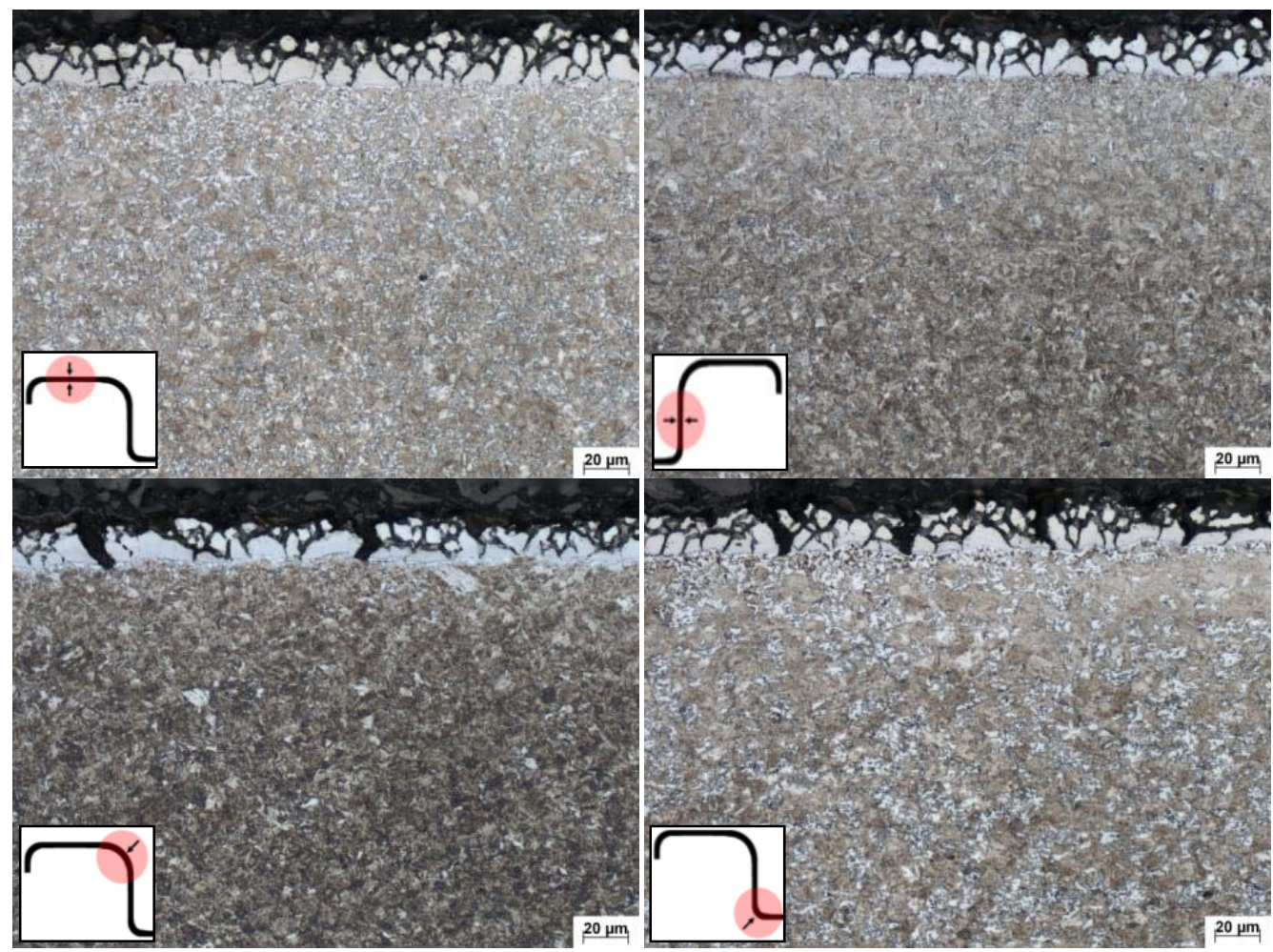

Figura 7. Aspectos característicos da microestrutura do aço 22MnB5-GA, após CTS, processado na melhor condição na CGL. Ampliação original 500 vezes.

Para a análise de trincas no substrato foram escolhidas regiões de dobramento e de estiramento. De acordo com Drillet at al [3], as regiões de estiramento estão sujeitas apenas ao surgimento de microtrincas $(<20 \mu \mathrm{m})$, provocadas pelo atrito da peça com o ferramental. Uma análise via MEV nesses locais poderia indicar a existência e possíveis mecanismos de nucleação, seja por penetração de metal líquido ou de corrosão sob tensão. Contudo, conforme mostrado na figura 7 , as peças produzidas nas melhores condições de galvannealing e de conformação estão isentas de trincas no substrato, independente da região analisada, ou seja, ao longo de todo o perfil da peça. 


\subsection{Caracterização do Revestimento após Fosfatização e Pintura}

Na figura 8 são mostrados, respectivamente, aspectos representativos das amostras apenas fosfatizadas e fosfatizadas e pintadas, ambas com superfícies antes e após jateamento. As análises via difração de raios- $X$ na superfície das amostras apenas fosfatizadas evidenciaram a formação das fases hopeíta $\left(\mathrm{Zn}_{3}\left(\mathrm{PO}_{4}\right)_{2}{ }^{*} 4 \mathrm{H}_{2} \mathrm{O}\right)$ e fosfofilita $\left(\mathrm{Zn} 2 \mathrm{Fe}\left(\mathrm{PO}_{4}\right)_{2}{ }^{*} \mathrm{H}_{2} \mathrm{O}\right)$. A fosfofilita é tipicamente observada em camadas de fosfato de aços não revestidos. Nas faces não jateadas foi identificada a fase zincita $(\mathrm{ZnO})$. Esses resultados indicam a existência de uma camada de fosfato, de acordo com o esperado para se obter boa pintura.

De um modo geral, a qualidade da pintura nas superfícies jateada e não jateada foi muito boa, sem defeitos superficiais. Os resultados das medições da espessura e da aderência da película seca de tinta indicaram não haver desplacamento da película em nenhuma das faces, independente do tratamento térmico praticado.

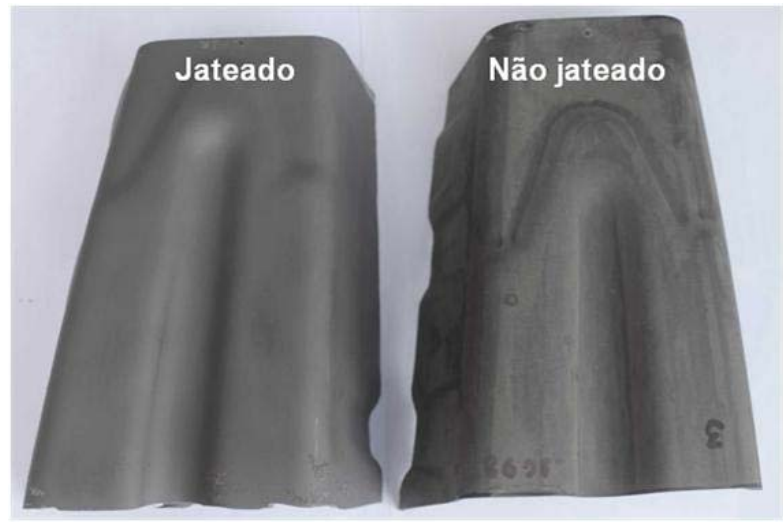

(a) Superfícies fosfatizadas

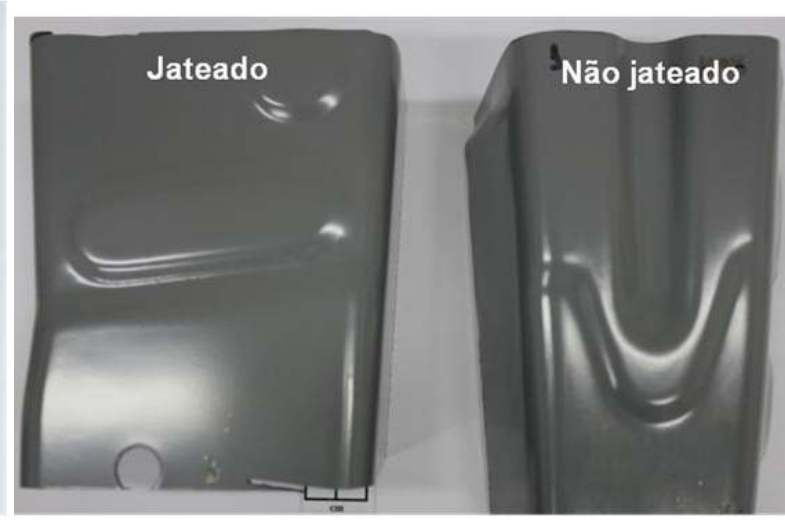

(b) Superfícies pintadas

Figura 8. Aspectos representativos do aço conformado a quente após fosfatização e pintura.

\section{CONCLUSÃO}

Os ciclos de recozimento e de galvannealing do aço 22MnB5-GA para aplicação em conformação a quente foram determinados em escala de laboratório e a sua produção validada em escala industrial. As suas características químicas e microestruturais, ligeiramente diferentes dos revestimentos destinados a estampagem a frio, contribuíram para que as peças conformadas a quente possuíssem boa qualidade superficial e fossem isentas de trincas no substrato.

Os ciclos térmicos de austenitização e os testes de conformação a quente com têmpera simultânea também foram realizados em escala piloto, com um aparato construído especialmente para o desenvolvimento desse produto.

Os tratamentos térmicos praticados com temperatura de forno até $950^{\circ} \mathrm{C}$ e tempos de até $5,0 \mathrm{~min}$, produziram os efeitos necessários para suportar a aplicação de conformação a quente. Contudo, significativos ganhos de qualidade do revestimento e do substrato foram alcançados com temperaturas intermediárias e menores tempos de tratamento, além de um controle da taxa de aquecimento.

Após conformação a quente, o revestimento é constituído por duas camadas distintas. Uma de solução sólida $\mathrm{Fe}_{\alpha}-\mathrm{Zn}$ (30\% a $40 \%$ de $\mathrm{Zn}$, em massa), 
homogênea, compacta, com poucas trincas, espessura em torno de 18,0 $\mu \mathrm{m}$ e completamente aderida ao substrato. Acima dessa camada há outra, constituída por compostos intermetálicos $\mathrm{Fe}-\mathrm{Zn}$ e ilhas de solução sólida $\mathrm{Fe}_{\alpha}-\mathrm{Zn}$. Essa região mais rica em $\mathrm{Zn}$ na superfície melhora a resistência à corrosão, proporciona proteção galvânica ao aço e minimiza o risco de nucleação de trincas, comuns em outros tipos de revestimentos para essa aplicação. Na superfície, forma-se durante o tratamento, em função da atmosfera oxidante dos fornos, uma camada de óxidos de $\mathrm{Zn}, \mathrm{Al}, \mathrm{Mn}$ e Si, que protege o revestimento e garante a integridade da camada.

As propriedades mecânicas em tração das peças conformadas a quente processadas na melhor condição na CGL atendem perfeitamente aos requisitos de aplicação desse produto. A microestrutura do aço é composta predominantemente por martensita.

Os substratos de aço das peças produzidas estavam isentos de trincas, nas faces interna e externa, tanto nas regiões de dobramento quanto nas de estiramento.

As peças de aço 22MnB5-GA conformadas a quente apresentaram um comportamento satisfatório durante os processos de fosfatização e pintura automotivos, tanto na condição jateada com granalhas, para remoção dos óxidos superficiais, quanto na condição não jateada. Não houve desplacamento da pintura nos testes de aderência para ambas às condições.

\section{REFERÊNCIAS}

1 Barbosa AHA. Efeito das condições de galvannealing na qualidade do revestimento galvanizado a quente GA formado sobre aços de alta resistência contendo $P$ e $B$, Tese de doutorado, Belo Horizonte: Universidade Federal de Minas Gerais, 2010.

2 Guttmann M. Diffusive phase transformation in hot dip galvanizing, Materials Science Forum, 1994, v. 155-156, p. 527-548.

3 Drillet $P$, Grigorieva R, Leuillier $G$, Vietoris T. Study of cracks propagation inside the steel on press hardened steel zinc based coating - La Metallurgia Italiana - n. 1, 2012. 